\title{
¿QUÉ DISCURSO PARA LA \\ MORAL? \\ SOBRE LA DISTINCIÓN ENTRE APLICACIÓN Y \\ JUSTIFICACIÓN EN LA TEORÍA DEL DISCURSO PRÁCTICO GENERAL
}

\section{Introducción}

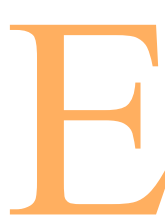

n este ensayo quiero ofrecer un breve análisis de la tesis elaborada por Klaus Günther según la cual «las cuestiones de validez de una norma tienen que separarse de las cuestiones de su aplicación» ${ }^{1}$. Se trata de una réplica a la conocida tesis del caso especial de Robert Alexy ${ }^{2}$ que Günther articula en dos ulteriores tesis: la primera es la necesidad de introducir el discurso de la aplicación de las normas para complementar el discurso de justificación; la segunda, circunscrita al razonamiento jurídico, consiste en la necesidad de explicar el razonamiento judicial como un discurso de aplicación, y por lo tanto, distinguir dentro del discurso jurídico entre una actividad de justificación y otra de aplicación de las normas jurídicas. A lo largo de estas páginas cuestionaré la corrección de una concepción dualista del discurso práctico general, una concepción que distingue una actividad de aplicación de otra de justificación de las normas.

\section{El carácter discursivo de la justificación de las normas}

Toda norma, así comienza el principal trabajo de Günther ${ }^{3}$, contiene una referencia, por tenue que ésta sea, a una situación de aplicación. También contiene una referencia a las consecuencias y efectos paralelos que producirá el cumplimiento de la norma. Ambos, no son elementos desconectados entre sí, sino que su relación determinará la validez, y por lo tanto la justificación de la norma.

\footnotetext{
${ }^{1}$ K. Günther. The Sense of Appropriateness, traducido por J. Farrel. State Unilersity of New York Press. Albany. 1993. p. 11.

${ }^{2}$ Según ésta, el discurso jurídico es un caso especial del discurso práctico, es decir, una forma de discurso de justificación de norma (véase R. Alexy. Teoría de la argumentación jurídica, traducido por M. Atienza e I. Espejo. Centro de Es'tudios Constitucionales. Madrid. 1989).

${ }^{3}$ Me refiero al citado The Sense of Appropriateness.
} 
Se puede sostener que el paso de la situación de aplicación descrita en la norma a las consecuencias previstas en la misma tiene un carácter empírico. En este caso, dice Günther, el criterio de justificación de la norma es el denominado principio de universalidad semántico según el cual la identidad (semántica) entre la situación de aplicación descrita en la norma y la situación de aplicación del caso concreto justifica las consecuencias prescritas en la norma ${ }^{4}$.

Alternativamente se puede sostener, como hace Günther, que la transición de una situación de aplicación concreta a las consecuencias previstas en una norma tiene un carácter normativo. En este caso, el lazo entre la situación de aplicación y las consecuencias normativas lo ofrece el principio de universalidad discursivo (U en adelante siguiendo la terminología de Günther), lo que significa que «cada uno se pone en la posición de la otra persona, que esto se hace recíprocamente y que todos los interesados juzgan colectivamente si la norma corresponde a sus intereses comunes» ${ }^{5}$.

El principio $U$ establece un nexo entre la norma propuesta originariamente y los intereses contenidos en ella, por una parte, y los intereses de aquellos afectados, por la otra parte $^{6}$. En otras palabras, la norma estará justificada si los afectados por su cumplimiento la aceptan colectivamente, o mejor, aceptan las consecuencias y efectos de su aplicación. El discurso determina,

\footnotetext{
${ }^{4}$ Las normas son enunciados que repiten una misma estructura: una descripción de una situación concreta y un mandato de deber ser en relación a las consecuencias y efectos paralelos de su aplicación. Alexy las ha sintetizado así: $(x) \mathrm{F} x \rightarrow \mathrm{G} x$ (Cfr. R. Alexy, Teoría de la argumentación jurídica, citado, pp. 81 y 214). Es decir, una norma en la que para toda situación F se dará (debe ser) la consecuencia G. El principio de universalidad semántico, tal y como ha sido formulado, justifica que en toda situación similar en sus aspectos relevantes a F se aplique la norma $(x) \mathrm{F} x \rightarrow \mathrm{G} x$ y por lo tanto, tengan lugar las consecuencias previstas $\mathrm{G}$. También Alexy lo sintetiza esquemáticamente así:

$$
\begin{aligned}
& \text { (1) }(x) \mathrm{F} x \rightarrow \mathrm{G} x \\
& \text { (2) } \mathrm{F} a \\
& \text { (3) } \mathrm{G} a
\end{aligned}
$$

Si hay una identidad entre la situación descrita $(\mathrm{F} x)$ en la norma y la situación de aplicación $(\mathrm{F} a)$, entonces la consecuencia prevista $(\mathrm{G})$ deber ser, debe acaecer. Günther dirige dos objeciones al principio de universalidad semántico. Brevemente, la primera es que enturbia la distinción entre justificación y aplicación de las normas, porque resolviendo una -la consideración de la situación de aplicación del caso- se soluciona la otra -la justificación de las consecuencias- (cfr. K. Günther, The Sense of Appropriateness, citado, p. 23). La segunda objeción al principio de universalidad semántico es que malinterpreta el objeto de la justificación, que no se refiere tanto a la norma en sí ( $(x) \mathrm{F} x \rightarrow \mathrm{G} x$ ) cuanto a la decisión $\mathrm{G} a$.

${ }^{5}$ K. Günther. The Sense of Appropriateness, citado, p. 23. La cursiva es mía.

${ }^{6}$ Ibídem p. 28. El carácter normativo que Günther atribuye a esta relación causal no significa el abandono del principio de universalidad semántico que será reconvertido en una regla de argumentación que garantiza «la transición de la evidencia empírica en las consecuencias para las necesidades de cada individuo y los efectos anejos para éste. cuando la norma se aplica, a la norma que contiene un interés general» (ibídem p. 27).
} 
en primer lugar, el objeto de la deliberación, esto es, los intereses individuales afectados por el cumplimiento de la norma; y en segundo lugar, la forma en que éstos serán considerados, es decir, recíprocamente ${ }^{7}$.

\section{La versión débil del discurso de justificación}

Si una norma, como apenas he indicado, es válida cuando las consecuencias y efectos de su cumplimiento han sido recíprocamente aceptados por todos los afectados, sólo la consideración de una situación concreta permitirá determinar qué intereses resultan afectados y por lo tanto quiénes participarán en el discurso ${ }^{8}$. De esta forma, la anticipación de la descripción de una situación de aplicación parece ser el primer requisito para iniciar un discurso sobre la validez o la aceptación de una norma concreta. Sobre cuál sea el contenido de esta descripción, es el interrogante que Günther resuelve confrontando dos versiones de $\mathrm{U}$ que se diferencian, esencialmente, en la situación ideal o real de deliberación en la que tiene lugar la justificación de las normas.

\section{1. Dos interpretaciones de $U$}

$L a$ versión fuerte de $U$. Esta primera versión de U propone una abstracción de la situación de aplicación tal que incluya todos los aspectos relevantes para los intereses de cada individuo, es decir, que contenga la completa descripción de la situación de aplicación $n^{9}$.

A la versión fuerte de $\mathrm{U}$ le corresponde una versión también fuerte del discurso de justificación según la cual «una norma es válida y en cada caso apropiada si las consecuencias y efectos paralelos que se producen para los intereses de cada individuo como resultado del cumplimiento general de esta norma en cada situación particular pueden ser aceptados por todos $\left.{ }^{10}\right\rangle$.

Las normas cuya aceptación se discute deberán anticipar todas las situaciones en las que pueda aplicarse, de manera que sus aspectos son obvios y los intereses de los afectados evidentes ${ }^{11}$. Ahora bien, esto sólo es posible si el discurso de justificación tiene lugar en condiciones ideales de deliberación

\footnotetext{
${ }^{7}$ Cada individuo tiene que asumir los intereses de los demás con el fin de apreciar la intensidad de cada interés involucrado. Se evita así que sólo sean relevantes los intereses de la mayoría o de un grupo (ibídem $\mathrm{p}$. 32).

${ }^{8}$ Ibídem p. 33.

${ }^{9}$ Sólo así se sabrá qué intereses resultan afectados y por lo tanto qué intereses deben incorporarse a la norma y quiénes deben participar en la justificación de la misma. Esta opción consiste en una absoluta coincidencia, en lo relevante, entre la situación descrita en la norma y la situación de aplicación concreta.

${ }^{10}$ Ibídem. La cursiva es mía.

${ }^{11}$ Ibídem. p. 34.
} 
(de tiempo y conocimientos ilimitados). La objeción, por lo tanto, es simple: puesto que la situación de deliberación es real (es decir, de tiempo determinado y conocimientos limitados), es imposible anticipar la completa descripción de una (toda) situación de aplicación.

La versión débil de $U$. Günther propone otra versión de $\mathrm{U}$ y del discurso de justificación: la versión débil, según la cual la descripción de una situación de aplicación debe hacerse dentro de los límites de tiempo y de conocimientos en los que tiene lugar el discurso práctico ${ }^{12}$. Habermas ha introducido este concepto de validez discursiva según el cual en la justificación de una norma sólo tienen que considerarse las consecuencias y efectos paralelos de una norma que puedan anticiparse: «Aunque $\mathrm{U}$ hable de "cumplimiento general", el criterio de validez no se refiere a todas las situaciones previstas desde un punto de vista absoluto; en su lugar, se refiere a las consecuencias y efectos paralelos previstos en un momento concreto, en tanto que son relevantes para los actuales intereses de cada individuo y son aceptados colectivamente por todos» ${ }^{13}$.

Con esta versión débil de U se logra incluir los innumerables cambios de intereses en la deliberación discursiva provocados por la imposibilidad empírica de adelantar todas las situaciones de aplicación de una norma. En otras palabras, se logra adaptar U a las condiciones reales del discurso quedando enunciado de la siguiente forma: «Una norma es válida si sus consecuencias y efectos paralelos que produce a los intereses de cada individuo como resultado del cumplimiento general de la norma bajo circunstancias inmutables pueden ser aceptados por todos $\rangle^{14}$.

Esta interpretación débil de U garantiza que para la justificación de una norma se omita la valoración de todos los aspectos relevantes de todas las posibles situaciones de aplicación y se consideren sólo aquellos aspectos que permanezcan inalterables en todas las situaciones de aplicación: «En un discurso sobre la validez sólo se es capaz de examinar los aspectos, de la descripción de una situación que son iguales en cada caso de aplicación» ${ }^{15}$.

\footnotetext{
${ }^{12}$ Además de que la abstracción de la situación de aplicación se hará dentro de los límites de tiempo y conocimiento, la versión débil de U consigue mantener inalterado el concepto de validez, en cuanto que sigue dependiendo de ¡a aceptación de las consecuencias y efectos a los intereses individuales por parte de todos. Günther no considera, sin embargo, que el discurso de justificación, incluso en su versión débil, deba reconocer un límite en la participación de los afectados (cfr. ibídem, p. 35).

${ }^{13}$ Ibídem.

${ }^{14}$ Ibídem. La cursiva es mía. Nótese que Günther sólo se refiere a la validez de la norma y no a su validez $\mathrm{y}$ adecuación como mencionaba al enunciar la versión fuerte de $\mathrm{U}$.

${ }^{15}$ K. Günther, «Normative Conception of Coherence and Discursive Theory». en Ratio Juris, n. 2, 1989, p. 158. Éste es el significado de una norma válida all things being equal o bajo circunstancias inmutabies (ibídem, p. 163).
} 


\section{La distinción entre justificación y aplicación de las normas morales}

La versión débil de U permite, según lo apenas indicado, considerar una situación real de deliberación. Es más, la versión débil de U logra adaptar el discurso sobre la validez de las normas a las condiciones de tiempo finito y conocimientos limitados. Junto a esta cualidad de U, Günther destaca otra: la de afrontar correctamente un conflicto de normas válidas. El planteamiento de un conflicto de normas y su correcta solución (gracias a la versión débil de U) será la estrategia argumentativa elegida por Günther para desarrollar su tesis más conocida; me refiero, por supuesto, a la necesaria introducción del discurso de aplicación en el ámbito de la deliberación práctica.

Existen situaciones concretas, inicia el concepto de conflicto de normas, en las que es posible aplicar no una sino varias normas que afectan a intereses individuales. Entonces, «dos normas, independientemente aplicadas (a la misma situación), alcanzan resultados incompatibles entre ellos, es decir, logran dos juicios morales contradictorios» ${ }^{16}$.

Para quienes sostienen, artificial mente, una versión fuerte de $\mathrm{U}$, el conflicto de normas se resolverá mediante una actividad de justificación (en su versión fuerte) según la cual una norma es válida cuando al sumarle las circunstancias relevantes del caso concreto es aceptada por todos. Esta solución esconde, tras su aparente simplicidad, una inversión del procedimiento discursivo porque primero se resuelve la aplicación de la norma, es decir, la completa descripción del caso concreto, y luego su justificación, es decir, la aceptación recíproca de sus consecuencias ${ }^{17}$. Tal inversión significa que para cada situación concreta los participantes de un discurso práctico deben afrontar una tabula rasa moral, puesto que todas las normas son inválidas salvo una que además será la norma adecuada al caso concreto.

Para la versión débil del discurso de justificación, sin embargo, todas las normas son válidas, y por supuesto también lo son las normas en conflicto, porque han sido aceptadas por todos en condiciones inmutables. En otras palabras, su validez, su aceptación, no depende de la completa descripción del caso de aplicación, sino de una descripción all things being equal. De las normas (válidas) en conflicto, sólo una será la norma adecuada a la situación concreta. La llave para solucionar el conflicto de normas válidas no será, por lo tanto, la aceptación de una norma en detrimento de otra, sino la adecuación de una de ellas a la completa situación de aplicación. Esta actividad,

\footnotetext{
${ }^{16}$ Ésta, que es una definición de Alexy, ha sido también aceptada por Günther. Ibídem. p. 207.

${ }^{17}$ K. Günther, «Normative Conception of Coherence and Discursive Theory», citado, p. 160.
} 
ajena al discurso de justificación, es el contenido del discurso de aplicación de normas ${ }^{18}$.

Antes de analizar con más detenimiento en qué consiste este discurso de aplicación de las normas, quiero reiterar que el concepto de conflicto de normas válidas no parece que encuentre su solución por vía del discurso de justificación débil. Esta versión, sin embargo, sí permite afrontarlo correctamente al separar las cuestiones aceptación de las normas de aquellas de descripción del caso concreto. En otras palabras, la versión débil de U esconde una tesis más relevante para este ensayo: la necesidad de distinguir entre un discurso de justificación y un discurso de aplicación de las normas.

El criterio de distinción entre el discurso de justificación y el discurso de aplicación de las normas morales, es su diverso contenido. La justificación es, según Günther, un discurso práctico sobre la validez de las normas, independientemente de la situación individual o concreta en la que serán aplicadas. El discurso de aplicación, por otro lado, está centrado en la adecuación de las normas a las circunstancias relevantes del caso concreto. El núcleo de este discurso es el si y el cómo se debe seguir una norma, en una situación particular y consideradas todas las circunstancias relevantes ${ }^{19}$.

Justificación y aplicación son dos formas discursivas complementaria ${ }^{20}$ validez y adecuación dos criterios de corrección complementarios. Allí donde no llega la justificación, es decir, a la consideración de todos los aspectos relevantes de una situación de aplicación, comienza la aplicación de la norma. El criterio de distinción entre justificación y aplicación no es otro que la distinta relevancia práctica atribuida a la situación concreta en uno y otro discurso: irrelevante para el primero, necesario para el segundo.

Concluye así el razonamiento a favor de una concepción dualista del discurso práctico general que distingue discurso de justificación y discurso de aplicación. Una argumentación que queriendo se puede resumir en los siguientes puntos: a) todas las normas son válidas si han sido aceptadas bajo circunstancias que permanecen invariables para cada situación de aplicación; b) estas normas son razones prima facie aplicables porque son insuficientes para sostener su aplicación a una situación concreta, o en otras palabras, su validez no contiene su aplicación; c) las normas válidas colisionan entre sí cuando se consideran los aspectos relevantes de una situación

\footnotetext{
${ }^{18}$ La actividad de aplicación de las normas consiste, básicamente, en describir el caso concreto de aplicación en sus aspectos relevantes para determinar qué norma es la adecuada.

${ }^{19}$ Cfr. K. Günther, The Sense of Appropriateness, citado, pp. 37-38.

${ }^{20}$ Cfr. K. Günther, «Normative Conception of Coherence and Discursive Theory», citado, p. 159.
} 
de aplicación concreta ${ }^{21}$. Entonces comienza una actividad discursiva, distinta a la de validez, que pretende la aplicación adecuada de una de las normas en conflicto.

\section{La lógica del discurso de aplicación}

La actividad de aplicación de las normas se podría definir como la solución de un conflicto de normas válidas mediante la descripción en sus aspectos relevantes de un caso concreto a fin de determinar cuál de las normas en conflicto es la adecuada al caso. Creo que de esta definición inicial son de destacar dos ideas que condicionarán el contenido lógico del discurso de aplicación: la primera es la ya mencionada irrelevancia de la validez de las normas en el discurso de su aplicación; la segunda, la que a continuación desarrollaré, es la necesidad de describir una situación en sus aspectos más relevantes, para así decidir cuál de las normas válidas (en conflicto) es la adecuada al caso concreto.

Un ejemplo para el discurso de aplicación. Para llevar a buen puerto la labor que ahora me propongo, el análisis del contenido del discurso de aplicación, propondré un ejemplo en el que dos normas válidas entran en conflicto una vez considerada la situación concreta, dando así comienzo al discurso de aplicación.

En mi ejemplo, utilizaré al Dr. Ravic, el médico protagonista del libro Arc de Triomphe de Erich Maria Remarque ${ }^{22}$. Éste se ve obligado a refugiarse de los nazis en Francia (como se sabe la obra se desarrolla en plena expansión del III Reich en Europa), donde ejerce su profesión de manera clandestina por no tener regularizada su situación. El Dr. Ravic, además, ha vivido la experiencia de un campo de concentración, y el temor a ser descubierto y devuelto a la Gestapo le atormenta. Paseando por París tropieza con un accidente laboral. Un albañil se precipita al vacío, con tan mala suerte que la viga que lo sostenía cae también y golpea fatalmente a una transeúnte. El hombre fallece en el acto y la mujer recibe heridas que requieren una rápida intervención médica. En la obra original Ravic socorre inmediatamente a la mujer. Yo quisiera, sin embargo, racionalizar su decisión y explicar el razonamiento práctico que justificó la acción del Dr. Ravic.

El Dr. Ravic sabe que una inmediata intervención de un médico salvará la vida de la mujer accidentada. Ahora bien, también es consciente de que

\footnotetext{
${ }^{21}$ «Por lo tanto -dice Günther-, en el discurso de aplicación se afronta el problema del conflicto de normas. Las normas que son válidas en circunstancias inmutables pueden colisionar unas con otras cuando se consideran todas las circunstancias de una situación... El conflicto de normas sería así un problema de su adecuación y no de su validez» (K. Günther, The Sense of Appropriateness, citado, p. 212).

${ }^{22}$ Véase E. M. Remarque, Arc de Triomphe, Kiepenheuer \& Witsch, Köln, 1945.
} 
al involucrarse en el accidente llamaría la atención de la policía francesa que descubriría su situación ilegal en Francia, lo expulsaría del país convirtiéndose entonces en un fácil objetivo para la Gestapo. Ésta creo que sea una perfecta situación para ejemplificar un conflicto de normas morales válidas en circunstancias inmutables que se pueden formular de la siguiente manera: hay que socorrer a un herido grave ( $\mathrm{N}$ 1) y hay que asegurar la propia seguridad (N 2) en peligro desde que la expulsión de Ravic a un país nazi podría tener como consecuencia su arresto por la Gestapo (llegando a poder ser confinado en un campo de concentración). Ambas reglas morales son válidas en el sentido débil de U, es decir, han sido aceptadas por todos (los afectados) en circunstancias inalterables para distintos casos. Son, además, consistentes entre sí porque en la situación que describen no colisionan. Ahora bien, la colisión o el conflicto de normas válidas se plantea cuando se consideran las circunstancias del caso concreto, en mi ejemplo, cuando Ravic, para socorrer y salvar la vida de la mujer herida, tiene que descubrir su situación de ilegal poniendo en peligro su propia seguridad.

\section{1. Tres actividades para un discurso}

¿Qué hacer? ¿Ayudar a la mujer herida o evitar poner en peligro la propia seguridad? O bien, siguiendo el modelo de razonamiento práctico de Günther qué norma $\mathrm{N}$ 1 o $\mathrm{N} 2$ es la adecuada a la situación concreta de aplicación? Para responder a estos interrogantes, para justificar la acción, el Dr. Ravic tendría que llevar a cabo dos actividades complementarias entre sí. La primera es la descripción de la situación mediante la consideración de sus circunstancias relevantes. Conviene precisar que cuando Günther menciona las circunstancias de un caso concreto, no alude a elementos fácticos sino morales, es decir, a los aspectos que desde un punto de vista moral son sobresalientes para la descripción del caso concreto. La segunda actividad consiste en justificar tal descripción, es decir, justificar la elección de unas circunstancias (las relevantes) en detrimento de otras. Descripción y justificación de la descripción: éste es el contenido esencial del discurso de aplicación, en el que además se puede considerar otras actividades. De manera resumida, ésta es la lógica del discurso de aplicación: a) la veracidad de los datos que se tienen sobre la situación de aplicación; b) la completa descripción de la situación y la justificación de la elección de unos aspectos en detrimento de otros; c) la coincidencia entre la situación contenida en la norma y la situación de aplicación una vez descrita: la consistencia semántica.

De la veracidad de los datos. La veracidad de las proposiciones que describen una situación es una condición necesaria para la descripción completa ${ }^{23}$. En el ejemplo propuesto, se podría objetar que la mujer no esté herida

\footnotetext{
${ }^{23}$ Ibídem. p. 231.
} 
gravemente y que pueda esperar sin peligro para su vida hasta que llegue una ambulancia, o bien que la intervención del Dr. Ravic no lo involucrará en el accidente y que la policía no hará pesquisas sobre su identidad. En todo caso, estas objeciones no son objeto de un discurso práctico de aplicación sino de un discurso empírico y/o teórico ${ }^{24}$.

De la completa descripción de la situación. En una situación concreta, como la del Dr. Ravic, se puede sostener que lo sobresaliente en términos morales es que se ayude a un herido grave o, por el contrario, que se omita el deber de socorro si eso pone en peligro la propia seguridad. Una vez más, decidir qué circunstancias son relevantes en un caso concreto equivale a describir este caso en sus aspectos relevantes. Tal decisión, tal elección, tiene que ser justificada de manera que el participante de un discurso de aplicación está obligado a dar buenas razones que justifiquen, además, la modificación o la derogación de una norma que podía prima facie aplicarse al caso ${ }^{25}$.

El problema de la descripción y justificación de la situación de aplicación ha sido primorosamente planteado por Günther, que se pregunta: «¿De acuerdo a qué criterio pueden ser valoradas normas que colisionan en una situación sin que implícitamente se subsuma una argumentación apropiada en un discurso de justificación? $»^{26}$. Es decir, ¿de acuerdo a qué criterio se puede describir una situación de aplicación que permita, de un lado, determinar los aspectos relevantes, y que impida, de otro lado, que tal actividad se convierta en una justificación sobre la validez de las normas? ${ }^{27}$. Este interrogante no es en absoluto gratuito si se tiene en cuenta que criterios tales como las reglas de superioridad de Baier o los principios de optimización de Alexy ${ }^{28}$ no sirven tanto a la aplicación de normas cuanto a su justificación ${ }^{29}$.

Rechaza Günther los criterios materiales (que deberían a su vez ser objeto de un discurso de justificación ${ }^{30}$ ) y adopta en su lugar un criterio formal

\footnotetext{
${ }^{24}$ Ibidem.

${ }^{25}$ Cfr. K. Gfinther, «Normative Conception of Coherence and Discursive Theory», citado, p. 159.

${ }^{26} \mathrm{~K}$. Günther, The Sense of Appropriateness, citado, p. 240.

${ }^{27}$ La distinción entre discurso de justificación y de aplicación incide de nuevo en la imposibilidad de resolver problemas propios de un discurso, en este caso el de la descripción del caso, siguiendo el procedimiento de otro discurso.

${ }^{28}$ Por un lado, las reglas de superioridad establecen la relación entre todas las hipótesis normativas relevantes en un caso concreto; los principios de optimización, por otro lado, parten de la estructura abierta de los principios, de forma que es posible relacionarlos con las circunstancias de una situación concreta (ibídem, pp. 240-241).

${ }^{29}$ Estos principios dan prioridad a unos aspectos sobre otros, de manera que «determinan -según Güntherno sólo la aplicación de una norma sino también su justificación o su validez dependiendo de su posición en el balance con otras normas» (ibídem, p. 241).

${ }^{30}$ Ibidem.
} 
que responda a la lógica del discurso de aplicación: el principio de coherencia.

La coherencia a la que se refiere Günther no es un criterio de valoración sino que más bien resume una relación: la que debe existir entre la norma, el resto de normas que prima facie eran aplicables a un caso y, finalmente, la completa descripción de la situación: «Una norma en todas sus variantes semánticas y en relación con otras normas aplicables sea adecuada a la situación descrita completamente» ${ }^{31}$. Tanto la adecuación de la norma a una completa situación, cuanto la coherencia de la norma y los aspectos relevantes de una situación, carecen de un contenido material. Más bien resume las relaciones entre la norma y la situación descrita completamente (en el caso de la adecuación) y entre la norma adecuada, el resto de normas aplicables y la situación descrita (en el caso de la coherencia).

Los mencionados principios de adecuación y coherencia determinarán en el caso del Dr. Ravic qué norma aplicar de las dos válidas que están en conflicto, dependiendo de cuáles sean los aspectos morales de una situación que se consideran más destacables. Si la situación es descrita como «una persona debe garantizar su propia seguridad aunque sea en detrimento de socorrer a una persona malherida», entonces la norma adecuada es $\mathrm{N} 2$ según la cual «hay que asegurar la seguridad». Si por el contrario la situación se describe como «se debe asistir a un herido grave aunque ello vaya en detrimento de la propia seguridad», entonces la norma adecuada será $\mathrm{N} 1$ según la cual «hay que socorrer a los heridos» ${ }^{32}$.

Para justificar el aspecto más relevante de la situación, que en el caso del Dr. Ravic es su atención profesional a la accidentada, el criterio de coherencia justificará el mismo. De nuevo se trata de una relación entre la norma adecuada (hay que socorrer a un herido grave), las normas que resultaban también aplicables (hay que asegurar la propia seguridad) y la descripción de la situación (hay que ayudar a un herido grave aunque sea a riesgo de la propia seguridad).

De la consistencia semántica. Si bien la anterior descripción es la actividad central del discurso de aplicación de las normas, queda aún la subsunción de la norma adecuada al caso concreto. Es decir, falta por comprobar la consistencia semántica ${ }^{33}$ entre la descripción contenida en la norma

\footnotetext{
${ }^{31}$ Ibidem, p. 244.

${ }^{32}$ En ningún caso la norma aplicada es hay que socorrer a los demás aún a riesgo de la propia seguridad o hay que garantizar la propia seguridad aunque para ello se omita un deber de socorro porque ninguna de estas normas aparecían en el conflicto inicial, además del hecho de que son normas superfluas. Ibídem, p. 244.

${ }^{33}$ Esta actividad está ordenada según el mencionado principio de universalidad semántica que en el discurso de aplicación es reconducido a una regla de consistencia. Su función es permitir, primero, el paso de una situación a la descripción de la norma, y segundo, el paso a la conclusión de la misma, es decir, a los efectos y consecuencias previstas.
} 
adecuada y la completa descripción de la situación. Este problema de consistencia no es sino un problema de interpretación del sentido de la norma, de las palabras de la norma. Volviendo al ejemplo del Dr. Ravic, se puede sostener que dar a conocer la verdadera identidad del Dr. Ravic no significa poner en peligro su seguridad, o que la obligación de prestar ayuda a un herido recae especialmente sobre los médicos mientras que los demás estaríamos exentos de tal obligación. ¿Cómo interpretar quién está obligado a prestar ayuda? ¿Cómo interpretar que la propia seguridad está en peligro?

La solución de tales problemas de interpretación viene de la mano de las denominadas reglas del uso de la palabra (word usage rules) o reglas de interpretación. Éstas postulan la identidad semántica de los términos usados en la norma y en la descripción de la situación ${ }^{34}$ concentrada en su adecuada aplicación. Como correctamente advierte Günther, la aplicación (adecuada) de las normas no puede reducirse a esta identidad semántica. Una simplificación tal supondría un fatal error para el razonamiento práctico por dos razones. En primer lugar, porque la relevancia de los aspectos de una situación estaría predeterminada por lo que la norma considere como tal. Es decir, se considerarán como relevantes sólo los aspectos de una situación que coincidan con los recogidos en la situación descrita por la norma sin que tal elección resulte justificada. En segundo lugar, la reducción de la aplicación de la norma a una cuestión de consistencia semántica significa una confusión entre la actividad de justificación y de aplicación de la norma, e incluso se antepone la segunda a la primera.

\section{El discurso de aplicación ¿es realmente un discurso distinto?}

Las críticas que presentaré a continuación tienen por objeto la versión débil del discurso de justificación que sostiene Günther, y el contenido del discurso de aplicación a la luz del principio de coherencia como criterio formal.

\section{1. La versión débil del discurso de justificación}

La primera tesis del razonamiento de Günther que culmina con la distinción entre discurso de justificación y de aplicación era precisamente la definición del primero como un discurso débil. Una norma es válida, dice

\footnotetext{
${ }^{34}$ Cfr. K. Günther, The Sense of Appropriateness, citado, p. 232. Al igual que otras reglas, las del uso de la palabra son objeto de un discurso sobre su validez, cosa que está fuera del alcance del discurso de aplicación. En el discurso jurídico, la justificación de estas reglas se realiza mediante los precedentes, los principios de la doctrina o los cánones de interpretación; en el discurso moral, estas reglas sólo pueden justificarse mediante otras normas válidas.
} 
esta versión débil, si las consecuencias y efectos de su aplicación son aceptados por todos bajo circunstancias que se consideran inalterables ${ }^{35}$.

A diferencia de lo que ocurre en un discurso de justificación formulado de manera fuerte, la validez de las normas, según su interpretación débil, no depende de su aceptación para cada caso concreto, es decir, no hay que adelantar todas y cada una de las posibles situaciones de aplicación de una norma. Un ejercicio tal es imposible en circunstancias de tiempo determinado y conocimientos limitados. El discurso de justificación (débil) asume así, y éste es su gran acierto, la situación real de deliberación en la que tiene lugar.

A pesar de este acierto, Günther genera cierta confusión cuando dice: «No hay, sin embargo, restricciones en relación con las personas admitidas: se le debe permitir la participación en el proceso de validez a todo aquel cuyos intereses puedan ser afectados por la aplicación de una norma $\rangle^{36}$.

Parece que Günther adapta el discurso de justificación a las condiciones reales del discurso práctico sólo deforma parcial, ya que acepta el límite de tiempo y conocimiento pero no el de participación en el discurso práctico. Alexy resume de manera impecable tal contradicción: el discurso de justificación en su dimensión empírica (tiempo y conocimiento) es real, mientras que en su dimensión de participación permanece siendo un discurso ideal ${ }^{37}$.

Una participación ilimitada, como indica Alexy, sólo puede realizarse de manera aproximada $^{38}$. Efectivamente, si una norma se acepta bajo circunstancias inalterables, significa que los afectados por el cumplimiento de la norma sólo pueden determinarse de manera aproximada y no absoluta. Habrá que esperar al caso concreto, a la consideración de sus aspectos relevantes para saber quiénes resultarán afectados en sus intereses. Si una participación limitada parece una condición obvia del discurso de justificación, cabe preguntarse entonces por qué Günther se resiste a aceptarla. La respuesta a esta cuestión concierne, como explicaré a continuación, a la distinción entre discurso de justificación y de aplicación y por extensión a su concepto débil de justificación.

En el discurso de justificación débil, el criterio de validez depende, debo repetirlo, de la aceptación de todos los afectados por el cumplimiento de una norma, bajo circunstancias que se consideran inalterables. El efecto de este concepto no es tanto la incorporación de las condiciones reales del discurso a la deliberación sobre la validez de las normas, cuanto la distinción

\footnotetext{
${ }^{35}$ Ibidem, p. 35.

${ }^{36}$ Ibídem.

${ }^{37}$ Cfr. R. Alexy, «Justification and Application of Norms», en Ratio Juris, n. 6, 1993, p. 159.

${ }^{38}$ Ibídem.
} 
entre un aspecto participativo y otro empírico que luego fundamentará la distinción entre justificación y aplicación.

En concreto, Günther asocia la participación (ilimitada) de los afectados a la aceptación de la norma y por lo tanto a su validez. Este sentido fuerte de participación contrasta con el aspecto empírico (limitado), que en el discurso de justificación queda reducido a la situación de aplicación considerada sólo en sus circunstancias inalterables. La norma ya es válida, en tanto que aceptada por todos, y la consideración de todos los aspectos de un caso concreto será irrelevante para la justificación. Günther logra así fundamentar la necesidad de introducir un nuevo discurso, el de aplicación, centrado en la deliberación de la concreta situación de aplicación.

Ahora bien, si el discurso de justificación tuviera lugar en condiciones de tiempo, conocimiento y participación limitada (cosa que Günther no acepta), la distinción entre un aspecto participativo (de aceptación) y otro empírico (tiempo y conocimientos limitados) no tendría sentido, y por lo tanto sería irrelevante una distinción entre justificación y aplicación de las normas. En concreto, sería imposible sostener un concepto de validez que estuviera determinado exclusivamente por la aceptación de todos los afectados. Junto a las restricciones de tiempo y conocimiento se deberán incorporar también límites a la participación. A este punto, convendría hablar de un discurso real, en lugar de una versión débil de justificación. La distinción relevante para el discurso práctico no sería tanto la de justificación/aplicación, cuanto la de discurso ideal y discurso real ${ }^{39}$.

Más categórica, si cabe, es la crítica de Weinberger en relación a la oposición entre discurso ideal y discurso real, una constante en toda la filosofía discursiva ${ }^{40}$. Sostiene que los filósofos de la teoría del discurso han (ab)usado la terminología teórica-discursiva pero han dejado de lado la complejidad del discurso real ${ }^{41}$.

La estrategia utilizada por la teoría discursiva, y ésta es una crítica igualmente extensible a Günther y a Alexy, ha sido la de justificar la necesidad de un discurso real mediante el discurso ideal. Es decir, la atención se ha dirigido no a la complejidad del discurso real sino a la elaboración de un modelo comunicativo, el discurso ideal, cuyas condiciones sólo pueden satisfacerse de manera aproximada. En opinión de Weinberger, más que de un discurso definido como el mejor, nos encontramos ante un discurso imposible,

\footnotetext{
${ }^{39}$ Ibídem. p. 160.

${ }^{40}$ Esta oposición explica la introducción del discurso de aplicación (en el caso de la tesis de Günther) o la tesis del caso especial (de Alexy).

${ }^{41}$ Cfr. O. Weinberger, «Basic Puzzles of Discourse Philosophy», en Ratio Juris, 1996. p. 177.
} 
cuyas condiciones no sólo no pueden realizarse aproximadamente, sino que además fracasa en su intento de dar requisitos indispensables para el discurso ${ }^{42}$.

Efectivamente, las características del discurso ideal, continuación ilimitada de la discusión, participación ilimitada, ausencia de poder, conocimientos universales, y corrección relativa $^{43}$ no son realizables de manera aproximada (tal y como sostiene Alexy) y por lo tanto no pueden servir de requisitos en un discurso como el real en el que se tiene que llegar a un límite: algunas personas no tienen capacidad para participar, no existe ninguna situación libre de poder, los participantes carecen de conocimientos divinos y la posibilidad discursiva es una noción demasiado débil ${ }^{44}$.

\subsection{El contenido del discurso de aplicación}

Si la crítica al discurso de justificación, tal como lo plantea Günther, se apoyaba en la confusión entre condiciones ideales o reales del discurso, la del discurso de aplicación se fundamenta también en otra confusión: en este caso entre actividad justificativa y de aplicación. Sostendré que el concepto de coherencia propuesto por Günther deja la puerta abierta a un discurso de justificación sui generis.

Como se recordará, en el discurso de aplicación resultaba de capital importancia la descripción completa de la situación a fin de determinar la adecuación de una norma al caso. Utilizando de nuevo el ejemplo del Dr. Ravic, la completa descripción, considerados sus aspectos relevantes, era formulada así: se debe asistir a un herido grave aunque ello vaya en detrimento de la propia seguridad. El principio de coherencia, como principio formal, justifica la elección de unos aspectos (el prestar ayuda a quien la necesita) en menoscabo de otros (gozar de cierta seguridad que en el caso del Dr. Ravic se traduce en evitar caer en manos de la policía francesa y luego en las de la Gestapo). Así descrita la situación, de las normas en conflicto, hay que socorrer a un herido y garantizar la propia seguridad, sólo una, la primera, será la adecuada en sus aspectos relevantes a la anterior descripción, y por lo tanto, será la norma que resulte aplicada.

Para Alexy una proposición como hay que socorrer a un herido aunque para ello haya que poner en peligro la propia seguridad no es tanto la descripción de una situación de aplicación, cuanto una decisión concreta, una norma individual nueva, en tanto que no deriva lógicamente ni de hay que

\footnotetext{
${ }^{42}$ Ibidem, p. 174.

${ }^{43}$ En el sentido de posibilidad discursiva.

${ }^{44}$ Cfr. O. Weinberger, «Basic Puzzles of Discourse Philosophy», citado, pp. 174-175.
} 
socorrer a un herido ni de no hay que poner en peligro la propia seguridad; y una norma, finalmente, cuyo contendido normativo hay que justificar ${ }^{45}$.

Incluso si se considerara que la proposición hay que socorrer a un herido aunque para ello se ponga en peligro la propia seguridad es la descripción del caso concreto (y por lo tanto carente de algún valor normativo), tal descripción necesitará ser justificada ${ }^{46}$. Efectivamente, en el discurso de aplicación hay que justificar la elección de los aspectos (moralmente) relevantes de cada situación. El criterio ofrecido para ello es el de coherencia, entendido como criterio formal ${ }^{47}$.

El concepto de coherencia, que representa una relación entre la norma adecuada, el resto de normas aplicables y la situación concreta, no sirve para determinar qué aspectos son relevantes en cada situación. Aquí reside su mayor defecto, que es un criterio vacío. De otro lado, sin embargo, su «metamorfosis» en un concepto material, más útil para determinar la relevancia de los aspectos morales de una situación, no significa sino la transformación del discurso de aplicación en un discurso de justificación.

Una última crítica que se puede dirigir a la teoría del discurso de aplicación es su fracaso a la hora de explicar el contenido de la actividad de aplicación de las normas. Günther indicaba que lo realmente relevante para el discurso de aplicación es el si y cómo se aplican las normas válidas. Una vez analizada la lógica de este discurso, parece que logre su objetivo sólo a medias. Aunque se aceptara que el discurso de aplicación consigue establecer qué norma aplicar (la norma adecuada), la teoría de Günther, sin embargo, se queda lejos de indicar cómo se debe aplicar esta norma al caso concreto. Aparentemente, resuelve tal carencia refiriéndose a la regla de consistencia semántica y a las reglas de interpretación. Sin embargo, indica también que éstas necesitan a su vez ser justificadas en un discurso sobre su validez. Se produce aquí una conexión entre justificación y aplicación que bien podría entenderse como una confusión entre ambas actividades.

\section{Conclusiones}

En el ámbito del discurso práctico general, la teoría de Günther representa un magnífico esfuerzo por adaptar la actividad discursiva a las condiciones

\footnotetext{
45 Ibídem. p. 165.

${ }^{46}$ «El discurso de aplicación y el principio de adecuación -sostiene Günther- sirven a la aplicación de normas válidas y a la justificación de la decisión concreta» (K. Günther, «Critical Remarks on Robert Alexy's Special-Case Thesis», citado, p. 155). La justificación a la que se refiere tiene como objeto la descripción del caso concreto.

${ }^{47}$ Günther rechaza otros criterios materiales, por considerar que ponen en peligro la exclusividad del discurso de aplicación, en otras palabras, porque permiten la introducción de cuestiones de validez en este discurso.
} 
reales de deliberación (si bien sólo de forma parcial en tanto que Günther acepta los límites de tiempo y conocimientos pero no de participación). Esta adaptación no requiere (como propone Alexy) la introducción del elemento institucional del derecho, y sí -he aquí el punto esencial de la obra de Günther- la introducción del discurso de aplicación.

La conclusión última de la teoría de Günther es la distinción dentro del razonamiento práctico general de dos actividades complementarias entre sí: la de justificación y la de aplicación de las normas. Creo, sin embargo, que esta distinción es más ficticia que real y que en definitiva fracasa el intento de justificar la introducción del discurso de aplicación.

Para aplicar adecuadamente una norma (válida), dice Günther, es necesario (debo reiterar las líneas esenciales del discurso de aplicación) la completa descripción de la concreta situación de aplicación en sus aspectos (morales) relevantes. Sólo esta descripción, sostiene Günther, permite determinar qué norma es la adecuada al caso. La elección de unos aspectos del caso concreto en detrimento de otros debe justificarse según el criterio de coherencia (interpretado como criterio formal). Se llega así a enunciados del tipo hay que socorrer ti un herido aunque ello ponga en peligro la propia seguridad que no son sino la descripción de un caso que justifica la aplicación de la norma adecuada. En otras palabras, en el caso concreto que he elegido como ejemplo se aplica la norma hay que socorrer un herido por que hay que socorrer a un herido aunque ello ponga en peligro la propia seguridad. En definitiva, lo que se consigue siguiendo el discurso de aplicación de Günther es justificar una decisión final mediante la justificación de una completa descripción del caso en sus aspectos relevantes. Si en lugar de aplicación se hablara de justificación de las normas en un sentido fuerte (según la versión fuerte de U), posiblemente se llegaría al mismo enunciado (hay que socorrer a un herido aunque ello ponga en peligro la propia seguridad) aunque más que descripción del caso se hablaría de norma (singular) cuyo contenido hay que justificar. En definitiva, tanto la actividad de adecuada aplicación cuanto la de justificación en sentido fuerte justifican una decisión final. A ésta se le puede denominar descripción del caso o enunciado normativo, hasta ahí las diferencias entre aplicación y justificación de las normas. 